Cita bibliográfica: López Redondo, J. (2018). Consumo doméstico de electricidad y forma urbana en la región metropolitana de Barcelona. Boletín de la Asociación de Geógrafos Españoles, 76, 329-357. doi: $10.21138 /$ bage. 2525

\title{
Consumo doméstico de electricidad y forma urbana en la región metropolitana de Barcelona
}

\author{
Electricity consumption and urban form \\ in the metropolitan region of Barcelona
}

\author{
Joan López Redondo \\ juan.lopez@uab.cat \\ Departamento de Geografía \\ Universitat Autònoma de Barcelona (España)
}

\section{Resumen}

El presente artículo analiza la relación entre la morfología urbana y el consumo de electricidad a partir del caso de la región metropolitana de Barcelona. Partiendo del estudio de las tipologías urbanas y de los consumos eléctricos domésticos, muestra cómo la menor densidad residencial y la vivienda unifamiliar, que tanto han proliferado en las últimas décadas en este ámbito, se asocian a mayores consumos eléctricos. La aportación presenta interés en el estudio de los costes de los procesos de metropolitanización, de su sostenibilidad ambiental y económica, así como, específicamente de los costes sociales de la difusión de la urbanización sobre el territorio.

Palabras clave: morfología urbana; densidad; dispersión; energía; electricidad.

\begin{abstract}
This article analyses the relationship between urban morphology and electricity consumption from the case of the metropolitan area of Barcelona. Based on the study of urban typologies and domestic electricity consumption, it shows how the lower density and single-family housing residential areas, which have proliferated in recent decades in the region, are associated with higher electricity consumption. The contribution is of interest in studying the costs of metropolitanisation processes,
\end{abstract}


their environmental and economic sustainability, and specifically to the social costs of the spread of urbanisation over the territory.

Key words: urban morphology; density; urban sprawl; energy; electricity.

\section{Introducción}

Uno de los rasgos más destacados del proceso de urbanización en España y en el conjunto de Europa es el incremento del consumo energético. Se trata de una dinámica con implicaciones extraordinariamente relevantes que se encuentra, de hecho, entreverada con los principales retos a los que deben hacer frente las sociedades contemporáneas: el proceso de cambio climático, las transformaciones demográficas y los patrones de producción y consumo (Smith, 2011; Kennedy, 2016). Uno de los ámbitos donde este incremento es más notable son las principales áreas metropolitanas. El caso de la región metropolitana de Barcelona es un ejemplo palmario de ello.

En efecto, el consumo doméstico de electricidad en la región metropolitana de Barcelona creció un 75\% entre 1992 y 2012, pasando de 3994,9 GWh a 7004,9 GWh. A pesar de que la población metropolitana también creció notablemente a lo largo de este periodo, el consumo de electricidad lo hizo a un ritmo muy superior, con lo que se pasó de 937 kWh por habitante en 1992 a 1387 en 2012, es decir, un incremento del $48 \%$ en tan sólo veinte años. ${ }^{1}$ Ahora bien, no todos los municipios de la región metropolitana de Barcelona muestran el mismo comportamiento. Así, a pesar de las dificultades para conocer de manera exacta el consumo de electricidad per cápita en un territorio caracterizado por una alta integración y movilidad, se puede constatar que algunos municipios presentan valores que llegan a doblar e incluso triplicar el de otros.

Las razones que explican estas diferencias son numerosas y de naturaleza diversa, y abarcan desde las características climáticas de cada lugar hasta la disponibilidad de fuentes de energía alternativas o el nivel de renta de la población. El presente artículo se centra en el estudio de una variable poco analizada pero que, a la vista de los resultados obtenidos, muestra tener una gran incidencia en el consumo final: la morfología urbana. Más allá de las características técnicas de las edificaciones en relación a la energía, variables como la tipología arquitectónica o la densidad de los tejidos urbanos presentan una clara relación con un determinado nivel de consumo.

Para analizar esta relación, el artículo se estructura en tres partes. La primera parte ofrece una panorámica de los trabajos dedicados al análisis de las consecuencias de los patrones seguidos por la ocupación del suelo. El reconocimiento parte de los impactos de carácter general provocados por determinadas pautas de ocupación para ir focalizando progresivamente en la relación entre

1 Los datos de consumo doméstico de electricidad han sido suministrados por el Institut Català de l'Energia (ICAEN). El cálculo de consumo por habitante del año 1992 se ha realizado sobre la población de 1991. 
forma urbana y energía y acabar con el consumo doméstico de electricidad específicamente. La segunda parte se inicia con la descripción del proceso de poblamiento de la región metropolitana de Barcelona durante las últimas décadas, descripción que ha de permitir explicar las diferentes pautas de ocupación del suelo que han convivido en este territorio. Estos patrones diversos de ocupación del suelo han tenido numerosas consecuencias que han sido ampliamente analizadas, si bien con un énfasis desigual con respecto a las variables consideradas. Finalmente, la tercera parte ensaya una estimación de esta última variable en el territorio de la región metropolitana de Barcelona. Así, la estimación del consumo de electricidad por habitante, la identificación de las diversas tipologías urbanas y, finalmente, su cruce, muestran la existencia de esta relación. ${ }^{2}$ De esta manera, el artículo aporta evidencia acerca del hecho que los tejidos urbanos de menor densidad y de tipología residencial unifamiliar tienen propensión a presentar consumos energéticos más elevados.

\section{El estudio de la relación entre consumo de energía y forma urbana}

El consumo de energía, y más concretamente de electricidad, y su relación con la forma urbana y las tipologías residenciales es, como se ha dicho, un tema poco estudiado no sólo en la región metropolitana de Barcelona sino en la mayor parte de áreas urbanas. Si bien las referencias son abundantes en cuanto a los estudios sobre la oferta y, especialmente, sobre la dotación de infraestructuras necesarias para suministrar energía, el consumo ha recibido tradicionalmente una atención menor, especialmente para ámbitos territoriales pequeños. ${ }^{3}$

La mayoría de análisis de la relación entre consumo de energía y tipología urbana se centran en la energía destinada al transporte. Madlener y Sunak (2011) o Mindali et al. (2004), por ejemplo, analizan la eficiencia en el consumo de energía destinada al transporte a partir de la comparación entre varias ciudades, pero sin distinguir entre las diversas tipologías urbanas que las componen. Un paso más allá, Steemers (2003) utiliza el concepto de "textura" de la ciudad y Norman, Mac Lean y Kennedy (2006) diferencian en sus análisis entre alta y baja densidad. En todos los casos, sin embargo, el análisis se limita, como se ha dicho, el transporte. Incluso el estado de la cuestión sobre "forma urbana, energía y medio ambiente" elaborado por Anderson, Kanaroglou y Miller (1996) se centra únicamente en la energía para el transporte y sus emisiones.

2 La última parte del artículo expone la metodología y algunos de los resultados obtenidos en el marco del proyecto de investigación Urban Fabric, Housing Typology and Electric Energy Consumption. La investigación ha sido llevada a cabo por el Grupo de Estudios sobre Energía, Territorio y Sociedad de la UAB con el impulso de la Enel Foundation entre 2013 y 2015, bajo la dirección de Oriol Nel•lo.

3 Entre los trabajos dedicados a la descripción del proceso de desarrollo de infraestructura energética en Cataluña cabe destacar, en el caso de la electricidad, los de Bartolomé (2007), Capel (1994) o Urteaga (2003), y en el caso del gas el de Arroyo y Cardoso (2009). Dos recopilaciones de trabajos en esta línea se pueden encontrar en Arroyo y Capel, 2002 y en Arroyo, 2003. 
Cuando los análisis tienen por objeto el consumo energético de los hogares según las tipologías urbanas, la mayoría parten de un enfoque arquitectónico y orientado a las características de la edificación (materiales empleados, dispositivos técnicos incorporados) más que a variables de tipo urbanístico. Responden a este tipo de trabajos centrados exclusivamente en la eficiencia energética de los edificios los de Heiple y Sailor (2008), los de Perez-Lombard, Ortiz y Pout (2008) o los Lewis, Ní Hógáin y Borghi (2013). En este sentido, son pocas las aproximaciones a partir de aspectos urbanísticos, es decir, que hagan referencia a elementos como la forma de los edificios, su orientación o la relación con otros edificios como variables determinantes del consumo energético final, si bien hay que destacar en esta línea desde los primeros trabajos de March y Martin (1975) al clásico de referencia de Alenxander, Ishikawa y Silverstein (1977) y los más recientes de Salat y Bourdic (2012), Ratti, Baker y Steemers (2005) Uihlein y Eder (2010). En todos ellos se pueden encontrar referencias específicas a aspectos como la distancia y la orientación de la fachada, el "ángulo de skyline urbano" o el "ángulo de obstrucción de la visión del cielo" y su impacto sobre el consumo energético de los edificios. Una línea de investigación más especializada, a la que corresponden trabajos como los de Akari y Konopacki (2005) o ShashuaBar y Hoffman (2000), es la que, más allá del ámbito estricto de la edificación, analiza el papel de la vegetación en las áreas urbanas como regulador de la temperatura y la reducción de energía que puede conllevar.

En el caso de la relación entre morfología urbana y consumo de electricidad estrictamente las referencias son aún menos abundantes y en muchas ocasiones se centran en las aplicaciones finales de la electricidad, como la calefacción, el aire acondicionado o los electrodomésticos, pero sin referencia explícita a la tipología residencial o la forma de los asentamientos en que se encuentran estas viviendas, como sería el caso de Bertoldi, Hiri y Labanca (2012) o de Howard (2012). Sin embargo, un grupo de estudios consideran la densidad como variable determinante del consumo de electricidad y, en algunas ocasiones, como el de Larivière y Lafrance (1999), se parte del análisis de la densidad para estimar el consumo de electricidad y otras energías en varias ciudades canadienses para concluir que, a pesar de que la alta densidad lleva asociado un consumo per cápita menor, esta reducción es muy inferior a la de la energía utilizada para el transporte. Wilson (2013) va un paso más allá y, a partir del análisis de tres condados de Illinois, establece una relación entre densidad urbana y consumo de electricidad que le lleva a destacar que las densidades más elevadas conllevan menores consumos, si bien las variables que mejor explican esta relación tienen que ver con el tiempo, el tamaño del hogar, el número de habitaciones o el tipo de calefacción.

En cualquier caso, los trabajos mencionados consideran únicamente una variable definitoria de la tipología urbana, la densidad, sin considerar aspectos como la dispersión o el tipo de edificación. Esta escasez de análisis puede ser debida a la insuficiencia de datos representativos sobre los que 
basarse. En este sentido, los institutos nacionales de estadística o los centros especializados en el sector energético representan las principales fuentes de información. En algunos casos, como el alemán, el portal de Destatis ofrece datos de consumo energético de los hogares desagregados por la fuente de energía y su aplicación final, pero sin llegar a distinguir por la tipología arquitectónica del edificio o la forma del tejido urbano en el que se encuentra. ${ }^{4}$ En el caso de Francia, el Centre d'Etudes et de Recherches Economiques sur I'Energie (CEREN) publica anualmente los datos de consumo eléctrico tanto para establecimientos de actividad industrial y terciaria como para residencias. Para este último caso, el último informe del CEREN (2013) ofrece resultados que distinguen los consumos entre casas y apartamentos. En España el Instituto para la Diversificación y Ahorro de la Energía (2011) publicó los resultados del proyecto SPAHOUSEC donde se detalla el consumo de electricidad hasta el nivel de aplicación final e, incluso, de electrodoméstico, distinguiendo por tipo de vivienda, si bien únicamente en dos categorías: unifamiliar y en bloque.

Sólo en contadas ocasiones se encuentran datos estadísticos exhaustivos sobre consumo de electricidad en función de las características del edificio y/o de la morfología urbana. Pero estos pocos casos permiten observar ya una relación entre ambas variables. Así, por ejemplo, en Inglaterra, las tipologías de casas aisladas consumieron en el año 2011 un promedio de 5400 kWh por hogar, mientras que en los pisos el consumo era de $3500 \mathrm{kWh} ;{ }^{5}$ en el caso de Noruega, el consumo medio de electricidad de las casas aisladas era el año 2012 más del doble de los pisos. ${ }^{6}$

En el área de Barcelona, más allá de los análisis centrados en un período histórico previo al analizado aquí, ${ }^{7}$ una de las pocas aportaciones en este sentido la constituye el trabajo realizado por la Direcció de serveis ambientals de l'AMB y Barcelona Regional (2014) para los 36 municipios del Área Metropolitana de Barcelona como parte del Plan de sostenibilidad ambiental de la AMB 2014-2020, donde, por otra parte, se destaca la dificultad para disponer de datos sobre consumo energético a nivel municipal.

Es decir, entre los costes que conlleva el diferencial entre los diversos modelos de ocupación del territorio, uno de los menos estudiados ha sido el del consumo doméstico de electricidad. Sin embargo, allí donde se dispone de información la relación entre forma urbana, tipología residencial y consumo de electricidad parece significativa. A pesar de no contar con datos expresamente

4 Destatis Statistisches Bundesamt. Recuperado de https://www. destatis.de

5 UK Government. Statistics. Recuperado de https://www.gov.uk/government/statistics/energy-consumption-in-the-uk

6 Statistics Norway. Energy consumption in households. Recuperado de http://www.ssb.no/en/energi-ogindustri/statistikker/husenergi

7 Véase, por ejemplo, Urteaga (1998). 
diseñados para este análisis, el siguiente apartado muestra las características de esta relación en la región metropolitana de Barcelona.

\section{Poblamiento y dispersión urbana en la región metropolitana de Barcelona}

La región metropolitana de Barcelona presenta una gran diversidad de tipologías urbanas, resultado de un proceso largo y complejo de ocupación del territorio. No se puede esperar otra condición de un ámbito sujeto a la presión de múltiples factores que han incidido sobre él y lo han moldeado durante siglos. Ahora bien, como en el conjunto de las grandes áreas urbanas españolas (Feria, 2011; Nel•lo, 2004), ha sido sobre todo en los últimos sesenta años cuando esta transformación ha mostrado un mayor dinamismo e intensidad. ${ }^{8}$

En líneas generales, los asentamientos urbanos habían seguido un patrón bastante homogéneo de ocupación del suelo hasta mediados del siglo XX. Este modelo se caracterizaba por la densidad de los tejidos y por la contigüidad de los nuevos desarrollos con las tramas existentes. Aparte del poblamiento disperso que tradicionalmente configuraban las masías y de las primeras operaciones urbanísticas destinadas a satisfacer una creciente demanda turística y de segunda residencia, pocas áreas residenciales escaparon a estas pautas generales de densidad y contigüidad. Así, hasta los años cincuenta del siglo pasado sólo las primeras urbanizaciones ligadas a la extensión de la red ferroviaria (en el Vallès, el Penedès, en el litoral del Maresme y el Garraf) responden a unas tipologías unifamiliares y a unas pautas de baja densidad (Nel•lo, 2011b). Todo esto cambia, sin embargo, a partir de mediados del siglo pasado, cuando la región metropolitana de Barcelona ve incrementar su población de forma súbita.

\subsection{Poblamiento}

En sólo treinta años, los que van de 1950 a 1981, la región metropolitana dobla su población, pasando de menos de dos millones de habitantes (1950 662) a más de cuatro (4 238 876). 9 El principal motivo de este crecimiento demográfico no se encuentra en un aumento de la fertilidad sino en la llegada de un importante flujo migratorio procedente mayoritariamente del resto de España. ${ }^{10}$ Como ha sido a menudo destacado, Cataluña había experimentado numerosos períodos

8 Hemos descrito de manera sintética el proceso de poblamiento y ocupación del suelo en la región metropolitana de Barcelona durante este periodo en López, 2011 y, más recientemente, en López, 2015.

9 Cifras de población según los censos homogeneizados de Goerlich y Mas, 2006.

10 Son muchos los autores que han descrito el proceso de poblamiento en Cataluña y la importancia que han tenido históricamente las migraciones. Véase, por ejemplo, Cabré (2007) o Arango (2007), así como el clásico de referencia de Nadal (1995). Véase igualmente Cabré y Pujadas (1989) o Pascual y Cardelús (1998). Para una descripción centrada en el ámbito metropolitano y en las dinámicas de poblamiento véase Nel•lo (2001). Para este mismo ámbito se puede encontrar una descripción acompañada de una completa información estadística en Serra (2003) o en su precedente Servei d'estudis territorials de la MMAMB (1994). 
de crecimiento demográfico en los últimos tres siglos, de los que los correspondientes a los últimos ciento cincuenta años fueron debidos en buena medida a la inmigración (Cabré, 1999). Ahora bien, la intensidad espacial y temporal del crecimiento ocurrido en este periodo constituye un rasgo nuevo.

A finales de la década de 1970 esta tendencia de crecimiento demográfico intensivo deja paso a un período de estancamiento. La crisis económica iniciada pocos años antes interrumpe el flujo inmigratorio y en el ámbito de la región metropolitana de Barcelona la población permanece estancada durante casi 20 años en una cifra siempre cercana a los 4,2 millones de habitantes. ${ }^{11}$ Desde un punto de vista territorial, sin embargo, no se trata en absoluto de un período anodino. En estas dos décadas aquellos municipios que a lo largo de los años anteriores habían acumulado población, en muchos casos hasta alcanzar densidades muy elevadas, comienzan a perder habitantes en favor de otros más periféricos. Como resultado, gran parte de los municipios de la primera y la segunda coronas metropolitanas ven incrementar su población con registros desconocidos hasta entonces. Los mismos factores que permitirán una necesaria desdensificación de buena parte de los núcleos urbanos comportarán en algunas ocasiones asentamientos de densidad notablemente más baja y, con ello, el surgimiento de unas nuevas pautas de ocupación del territorio.

Al final del siglo XX, como se ha dicho, la región metropolitana de Barcelona (y el conjunto de Cataluña) se encontraba todavía inmersa en un periodo de estancamiento demográfico. Ahora bien, a partir del cambio de siglo la población metropolitana empezó a crecer de manera repentina gracias principalmente a la reanudación del flujo inmigratorio, esta vez mayoritariamente de origen extracomunitario, hasta llegar a superar los cinco millones de habitantes, cifra que de nuevo se mantiene más o menos estancada a partir del año 2010. De nuevo son las principales ciudades y áreas urbanas las que acogen la mayor parte de esta población, por lo que pueden revertir los saldos demográficos negativos que habían mostrado durante las dos décadas anteriores (López, 2007). Ahora bien, el movimiento de redistribución interna de la población, precisamente desde estos núcleos urbanos hacia el resto del territorio, que había caracterizado la etapa anterior no se detiene. Conviven, así, dos dinámicas hasta cierto punto complementarias: la llegada a las grandes áreas urbanas de población extranjera y la salida de estas mismas áreas hacia el resto de municipios metropolitanos de población mayoritariamente autóctona.

11 Aparte de las referencias citadas, este período ha sido específicamente analizado por Pujadas y Mendizábal (1992) y por Serra (1997). 


\subsection{Ocupación del suelo}

Esta evolución del poblamiento tuvo como resultado un elevado consumo de suelo en la región metropolitana de Barcelona, no únicamente porque un mayor volumen de población requiere, lógicamente, un mayor espacio para vivir, sino también porque las pautas de redistribución de las últimas décadas fueron acompañadas en buena parte de los casos, como se ha explicado, por una disminución de las densidades. Sobre las 323.000 hectáreas de la región metropolitana de Barcelona surge, durante la primera etapa del período descrito, una forma de desarrollo urbano relativamente nueva: los polígonos de vivienda, de manera que, desde un punto de vista territorial, los desarrollos residenciales son contenidos con respecto a la ocupación de nuevo suelo y siguen, a veces incluso de manera excesiva, pautas de contigüidad respecto a los tejidos existentes.

Ahora bien, en paralelo a estas nuevas formas de urbanización que se añaden a las tradicionales, surgen y se extienden paulatinamente nuevas tipologías residenciales. Al principio estas nuevas tipologías no responden a la demanda de primera residencia, y ese es el principal factor que determina su tipología. En la mayoría de casos se trata, como se ha dicho, de áreas de baja densidad, ubicadas intencionadamente lejos de los principales núcleos urbanos, porque su función principal es la de segunda residencia, es decir, la de ofrecer a sus propietarios un lugar alternativo a su residencia habitual, condicionada por los inconvenientes de una textura urbana que se ha formado de manera precipitada, a menudo descontrolada, y que ha dado como resultado unos tejidos densos, infradotados de espacios verdes, servicios y equipamientos. Por este motivo, las nuevas áreas de segunda residencia buscarán precisamente lo contrario: ofrecer a una población que ha sido capaz de incrementar su renta, unas condiciones totalmente opuestas a las del lugar donde reside habitualmente.

Consumado el primer paso, el surgimiento de nuevas áreas exclusivamente residenciales, de baja densidad y alejadas de los núcleos urbanos existentes, el proceso en espiral ya se ha iniciado. Las mejoras infraestructurales y el incremento de renta propiciarán la migración de una parte de la población desde las áreas más densamente pobladas hacia lugares progresivamente más alejados a partir de la conversión de parte de las segundas residencias en primera.

Posteriormente, a los crecimientos "tradicionales" de la trama urbana, los polígonos residenciales y las viviendas aisladas todavía se sumarán otras tramas intermedias de ocupación del suelo. En parte por un progresivo agotamiento de las reservas de suelo residencial, y en parte por una mayor concienciación sobre las consecuencias negativas de este modelo de ocupación extensiva, las nuevas operaciones irán dando paso a densidades más elevadas: a las viviendas unifamiliares aisladas se añadirán las unifamiliares en bloque (las casas adosadas o en hilera) y, finalmente, las plurifamiliares en bloque de densidades moderadas. Ninguna de las tipologías mencionadas desaparece completamente, pero las pautas de dispersión, baja densidad y especialización que 
habían caracterizado los desarrollos residenciales durante muchos años pierden protagonismo progresivamente.

Resulta complicado evaluar de forma precisa e inequívoca este proceso de ocupación del suelo y, más aún, cuantificar la superficie de suelo residencial que responde a la triple característica de baja densidad, dispersión y segregación funcional, ya que las tres características se mezclan de manera diversa. Por este motivo, las cifras de que se dispone muestran algunas diferencias, en función de las variables que se han considerado. Así, como muestra la Tabla 1, Font y Carreras estimaron que de las 40996 hectáreas de suelo residencial transformado existentes en la región metropolitana en 200026865 hectáreas eran de baja densidad, es decir, un 65,5\% del suelo residencial total (Font y Carreras, 2006). ${ }^{12}$ El Plan territorial metropolitano de Barcelona calculó que de las 59423 hectáreas de suelo residencial y mixto unas 26016 hectáreas se encontraban ocupadas por las que se denominaron "áreas especializadas residenciales", es decir, aquellas que a las características de baja densidad y dispersión sumaban una fuerte especialización funcional, en este caso en residencia, y que representaban un $43,8 \%$ del total ${ }^{13}$. Por su parte, el Mapa Urbanístico de Cataluña cifra en 24510 hectáreas la superficie neta de suelo urbano residencial (es decir, sin considerar los sistemas) según el planeamiento vigente a 1 de enero de 2013, de las cuales 14195 hectáreas corresponden a la categoría de "casas aisladas", lo que representa un 57,9\% ${ }^{14}$. Finalmente, una superficialización a partir de las categorías de suelo residencial recogidas en la cuarta edición del Mapa de cubiertas del suelo de Cataluña, correspondiente al año 2009, muestra como de las 39549 hectáreas de suelo residencial de la región metropolitana de Barcelona, 25448 hectáreas, un 64,3\%, corresponde a las categorías "Viviendas unifamiliares", "Casas aisladas" o "Urbanizaciones". ${ }^{15}$

12 Con anterioridad, la ocupación del suelo en la región metropolitana de Barcelona había sido estudiada por Solans (2002) y por Carreras (2002).

13 Las bases cartográficas de las diversas tipologías urbanas utilizadas en el Plan territorial metropolitano de Barcelona se pueden encontrar en: http://territori.gencat.cat/ca/01_departament/05_plans/01_planificacio_territorial/ plans_territorials_nou / territorials_parcials / ptp_metropolita_de_barcelona /

14 La cifra corresponde a los "Datos básicos municipales y comarcales. Febrero 2014" del Mapa Urbanístic de Catalunya. El Departament de Territori i Sostenibilitat de la Generalitat de Catalunya actualiza las bases consultables en su portal con cada nueva actualización. Los datos más recientes pueden encontrarse en: http://territori.gencat.cat/ca/06_territori_i_urbanisme/urbanisme/mapa_urbanistic_de_catalunya/

15 Se trata de tres de las seis tipologías residenciales en que se clasifican las cubiertas del suelo en el Mapa de Cobertes del Sòl de Catalunya 2009 elaborado por el Centre de Recerca Ecològica i Aplicacions Forestals (CREAF), descrito en detalle más adelante. 
Tabla 1. Estimaciones del suelo residencial según su tipología

\begin{tabular}{|c|c|c|c|}
\hline \multicolumn{2}{|c|}{ Font y Carreras 2006} & \multicolumn{2}{|c|}{ Año de referencia: 2000} \\
\hline & $\begin{array}{l}\text { Suelo residencial de } \\
\text { baja densidad } \\
\text { (transformado) }\end{array}$ & $\begin{array}{l}\text { Suelo residencial } \\
\text { intensivo } \\
\text { (transformado) }\end{array}$ & $\begin{array}{l}\text { Total suelo } \\
\text { residencial } \\
\text { (transformado) }\end{array}$ \\
\hline Hectáreas & 26.865 & 14.131 & 40.996 \\
\hline$\%$ & 65,5 & 34,5 & 100,0 \\
\hline \multicolumn{3}{|c|}{ Pla territorial metropolità de Barcelona } & Año de referencia: 2006 \\
\hline & $\begin{array}{l}\text { Áreas especializadas } \\
\text { residenciales } \\
\text { (urbano y uble.) }\end{array}$ & $\begin{array}{l}\text { Núcleos urbanos y } \\
\text { sus extensiones } \\
\text { (urbano y uble.) }\end{array}$ & $\begin{array}{l}\text { Total suelo } \\
\text { resiencial y mixto } \\
\text { (urbano y uble.) }\end{array}$ \\
\hline Hectáreas & 26.016 & 33.407 & 59.423 \\
\hline$\%$ & 43,8 & 56,2 & 100,0 \\
\hline \multicolumn{2}{|c|}{ Mapa Urbanístic de Catalunya } & \multicolumn{2}{|c|}{ Año de referencia: 2013} \\
\hline & $\begin{array}{l}\text { Casas aisladas } \\
\text { (superficie neta) }\end{array}$ & $\begin{array}{l}\text { Resto de suelo } \\
\text { residencial } \\
\text { (superficie neta) }\end{array}$ & $\begin{array}{c}\text { Total suelo } \\
\text { residencial } \\
\text { (superficie neta) }\end{array}$ \\
\hline Hectáreas & 14.195 & 10.316 & 24.510 \\
\hline$\%$ & 57,9 & 42,1 & 100,0 \\
\hline \multicolumn{3}{|c|}{ Mapa de cobertes del sòl de Catalunya } & Año de referencia: 2009 \\
\hline & $\begin{array}{l}\text { Viviendas unifamilia- } \\
\text { res, casas aisladas y } \\
\text { urbanizaciones }\end{array}$ & $\begin{array}{c}\text { Centro urbano, } \\
\text { Ensanche, colonias y } \\
\text { núcleos aislados }\end{array}$ & $\begin{array}{l}\text { Total suelo } \\
\text { residencial }\end{array}$ \\
\hline Hectáreas & 25.448 & 14.101 & 39.549 \\
\hline$\%$ & 64,3 & 35,7 & 100,0 \\
\hline
\end{tabular}

Fuente: elaboración a partir de las fuentes citadas

Es decir, a pesar de las diferencias de cálculo según los datos que se consideren, las diversas estimaciones apuntan a que aproximadamente la mitad del suelo residencial de la región metropolitana de Barcelona correspondería en la actualidad a la mencionada triple característica de especialización, baja densidad y dispersión.

Aparte de la elevada cantidad de suelo que esta cifra representa, es importante destacar que se trata de un patrón relativamente nuevo en la región metropolitana de Barcelona. Así, según la última de las fuentes utilizadas, el 64,3\% del suelo residencial que en 2009 constituían los "Viviendas unifamiliares", "Casas aisladas" y "Urbanizaciones" constituía únicamente un 26,3\% en 1956, ya que de las 8996 hectáreas de suelo residencial existentes en ese momento tan sólo 3207 
correspondían a suelo "Urbanizado residencial laxo". ${ }^{16}$ El resultado es, como se puede apreciar en la Figura 1, una aceleración en las tasas de ocupación del suelo a lo largo de las últimas décadas.

Figura 1. Evolución del suelo ocupado en la región metropolitana de Barcelona

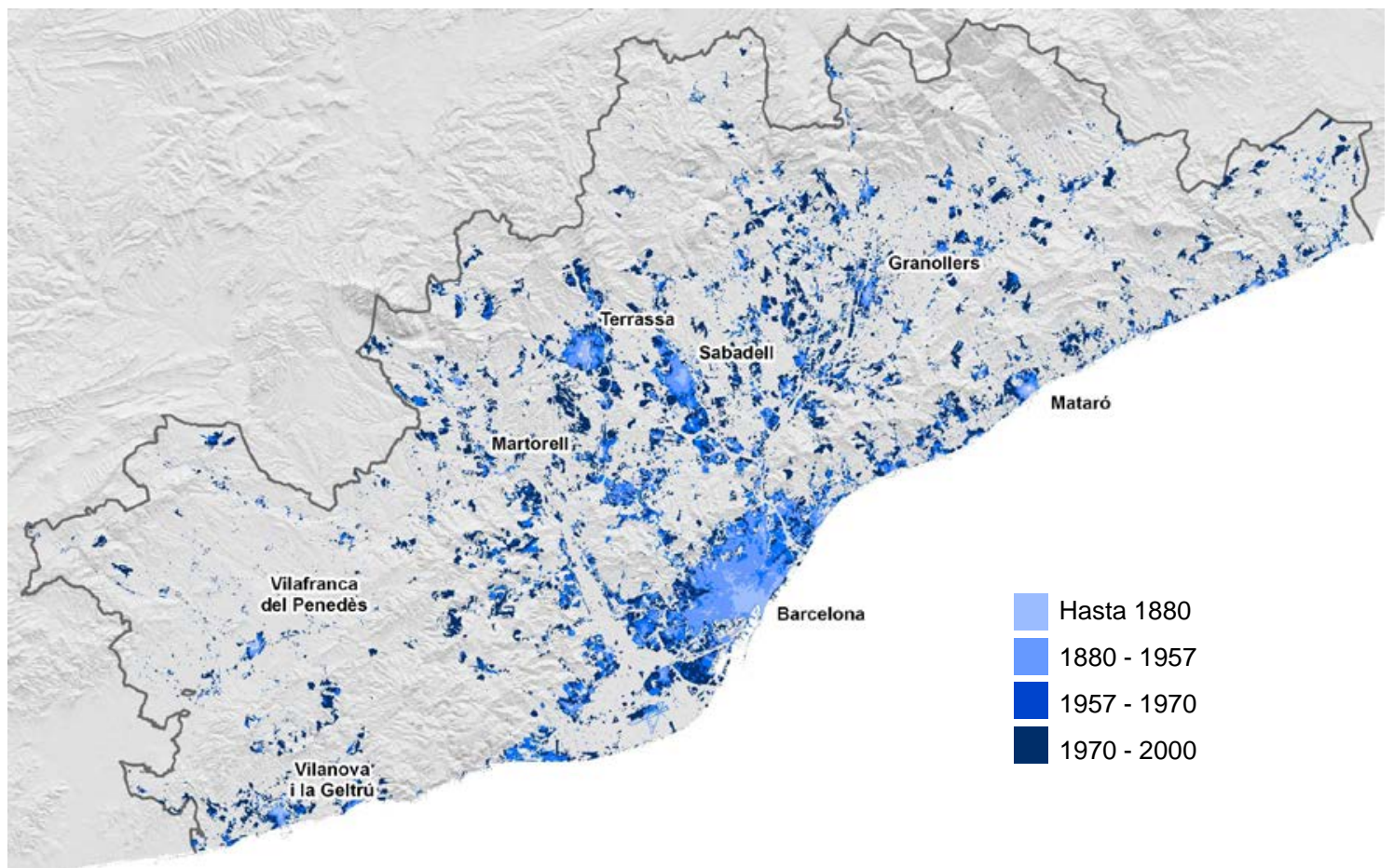

Fuente: López (2015)

Junto a los beneficios que la desdensificación o el aumento de las posibilidades a la hora de elegir el lugar de residencia hayan podido tener sobre los ciudadanos, beneficios que han recaído básicamente sobre los que protagonizaban estas migraciones residenciales, las nuevas pautas de ocupación del territorio metropolitano han tenido también importantes costes, la mayor parte de los cuales han recaído sobre el conjunto de la población. No es este el lugar para detallar los diversos costes y beneficios de esta pauta de ocupación del suelo que, por otra parte, han sido ampliamente analizados desde diversas aproximaciones. ${ }^{17}$ Ahora bien, el consumo de energía no ha sido una variable habitualmente estudiada en los análisis de la morfología urbana en la región metropolitana ni en otros lugares.

16 A diferencia del mapa de 2009, el Mapa de Cobertes del Sòl de 1956, realizado por la Diputació de Barcelona y el Centre de Recerca Ecològica i Aplicacions Forestals (CREAF) para la provincia de Barcelona, etiqueta su base de polígonos en tres niveles. El tercero de estos niveles distingue 53 categorías, de las que se han seleccionado dos, "Urbanizado residencial compacto" y "Urbanizado residencial laxo", por considerarlas propias y exclusivas del suelo residencial.

17 Descripciones de carácter general de los costes y beneficios de determinadas pautas de urbanización se pueden encontrar, por ejemplo, en Camagni, Gibelli, y Rigamonti, 2002. Para el caso específico de la región metropolitana de Barcelona, véase Rueda (2002), Muñoz (2005), Indovina (2007), Nel•lo (2011a), o varios de los textos recogidos en Muñoz (2011). Para un aspecto específico relacionado con el consumo, como es el agua, véase, por ejemplo Tello (2005) o Saurí (2005 y 2011). 


\section{Consumo doméstico de electricidad en la región metropolitana de Barcelona}

A la hora de estudiar la relación entre la forma urbana y el consumo doméstico de electricidad el primer obstáculo a superar lo constituyen las limitaciones de la información de base. Así, los datos disponibles sobre consumo doméstico de electricidad no reúnen los requisitos necesarios de desagregación territorial y cruce con otras variables para un análisis de estas características, y obligan a la estimación a partir de metodologías que integren las diversas fuentes de información existentes. Esta sección describe el proceso seguido para realizar esta estimación en la región metropolitana de Barcelona a partir de una descripción de la información disponible sobre consumo de electricidad y tipologías urbanas, su proceso de tratamiento y, finalmente, los resultados obtenidos de su aplicación.

\subsection{Consumo de electricidad por habitante de los municipios metropolitanos}

El consumo medio de electricidad en los hogares de la región metropolitana de Barcelona el año 2012 fue de 1389,52 kWh/hab. ${ }^{18}$ Como consumo medio, se trata del total de electricidad consumida en la región metropolitana para usos domésticos dividida por su población. Ahora bien, el reparto desigual de la población hace que esta media esté condicionada por los valores de los municipios más grandes. Por ello en el presente análisis no ha considerado el consumo medio sino la media de los consumos de los 164 municipios metropolitanos, que fue de 1628,26 kWh/hab.

Sobre esta media, los municipios metropolitanos muestran, como ya se ha apuntado, pautas de consumo muy diversas. Así, algunos municipios, especialmente los del entorno más inmediato a la ciudad de Barcelona (Santa Coloma, Badalona, I'Hospitalet de Llobregat) o algunas localidades vallesanas (la Llagosta, Badia del Vallès) tienen valores notablemente inferiores (por debajo de los 1100 kWh/hab), mientras que otros (Sitges, Gallifa, Sant Cebrià de Vallalta, Sant Quirze Safaja, Campins, Sant Vicenç de Montalt, Granera) duplican el consumo de éstos. ${ }^{19}$

Los resultados son sin duda ilustrativos y permiten ya una primera lectura. Sin embargo, presentan una limitación importante: los datos de población se refieren a los residentes empadronados en cada municipio, mientras que la información sobre electricidad recoge el consumo que se produce en todas las viviendas, sean éstas principales o secundarias, sin diferenciar el número de días que han sido ocupadas a largo del año. Esta limitación ha obligado a realizar una estimación de la población "real" en cada municipio.

18 Además de los citados datos sobre consumo de electricidad suministrados por el Institut Català de l'Energia (ICAEN), se han utilizado los datos de población a 1 de enero de 2013 que ofrece el Institut d'Estadística de Catalunya.

19 La desviación típica de la serie es de 319,9, lo que da un coeficiente de variación del 19,6\%. 
La estimación de esta población "real" se ha realizado a partir del número de residencias existente y de la proporción de viviendas principales y secundarias. ${ }^{20}$ Con este propósito, se ha calculado un incremento sobre la población empadronada en cada municipio equivalente al número de viviendas secundarias ${ }^{21}$ multiplicado por 80 (como estimación de los días de ocupación/año) y multiplicado a su vez por 3,5 (como estimación de las personas que, por término medio, ocupan estas viviendas secundarias).

Este cálculo comporta, lógicamente, un incremento de la población total de la región metropolitana, lo que, por otra parte, se considera poco probable, ya que la ocupación de las residencias secundarias viene protagonizada mayoritariamente por población residente en la misma región que realiza desplazamientos cortos de fin de semana o estancias vacacionales más largas. Al mismo tiempo, se considera que aquellas residencias secundarias metropolitanas ocupadas por residentes de fuera de la región se verán seguramente compensadas por la salida de residentes metropolitanos a otros ámbitos. Por este motivo se ha considerado que la estimación de la población "real" de cada municipio no debía significar un incremento de la población total de la región metropolitana, sino el mantenimiento de su volumen. Por ello, los incrementos de población "real" obtenidos para cada municipio han sido ponderados por su peso poblacional, de manera que la población que ocupa las residencias secundarias ha sido restada en su municipio de origen de manera proporcional a su peso demográfico. Con ello, entradas y salidas han quedado compensadas a nivel metropolitano, pero los municipios con fuerte proporción de residencias secundarias han visto como su población "real" es superior a la empadronada, mientras que los que tienen pocas residencias secundarias han visto disminuir el peso de su población. ${ }^{22}$

20 Cabe decir que el Institut d'Estadística de Catalunya publica desde el año 2002 las "Estimaciones de población estacional" para todos los municipios catalanes mayores de 5000 habitantes (ya sea por población empadronada o estacional). Ahora bien, este cálculo incluye, además de variables como la residencia principal o secundaria, otros no directamente vinculadas al consumo de electricidad de los hogares, como el turismo, la movilidad por trabajo o la movilidad por estudio. Por este motivo se ha preferido realizar un cálculo únicamente a partir de las dos primeras.

21 Los datos de vivienda por tipología corresponden al Censo de 2011. En algunos municipios que no disponían de este dato se ha calculado el número de viviendas secundarias como proporción de viviendas totales a partir de la aplicación del porcentaje medio de los censos de 2001 y 1991.

22 La formalización de este cálculo sería:

Para el incremento de población de cada municipio:

$$
\Delta P_{m}=S_{m} * q *\left(\frac{d}{365}\right)
$$

Donde: $\mathrm{P}=$ Población

$S=$ Residencias secundarias

$\mathrm{m}=$ municipio

$q$ = personas que ocupan cada residencia secundaria (3.5)

$\mathrm{d}$ = días de ocupación de la residencia secundaria al año (80) 
Los resultados del cálculo de consumo doméstico de electricidad para esta nueva población se muestran en la Figura 2.

Figura 2. Consumo doméstico de electricidad por habitante real de los municipios metropolitanos 2012

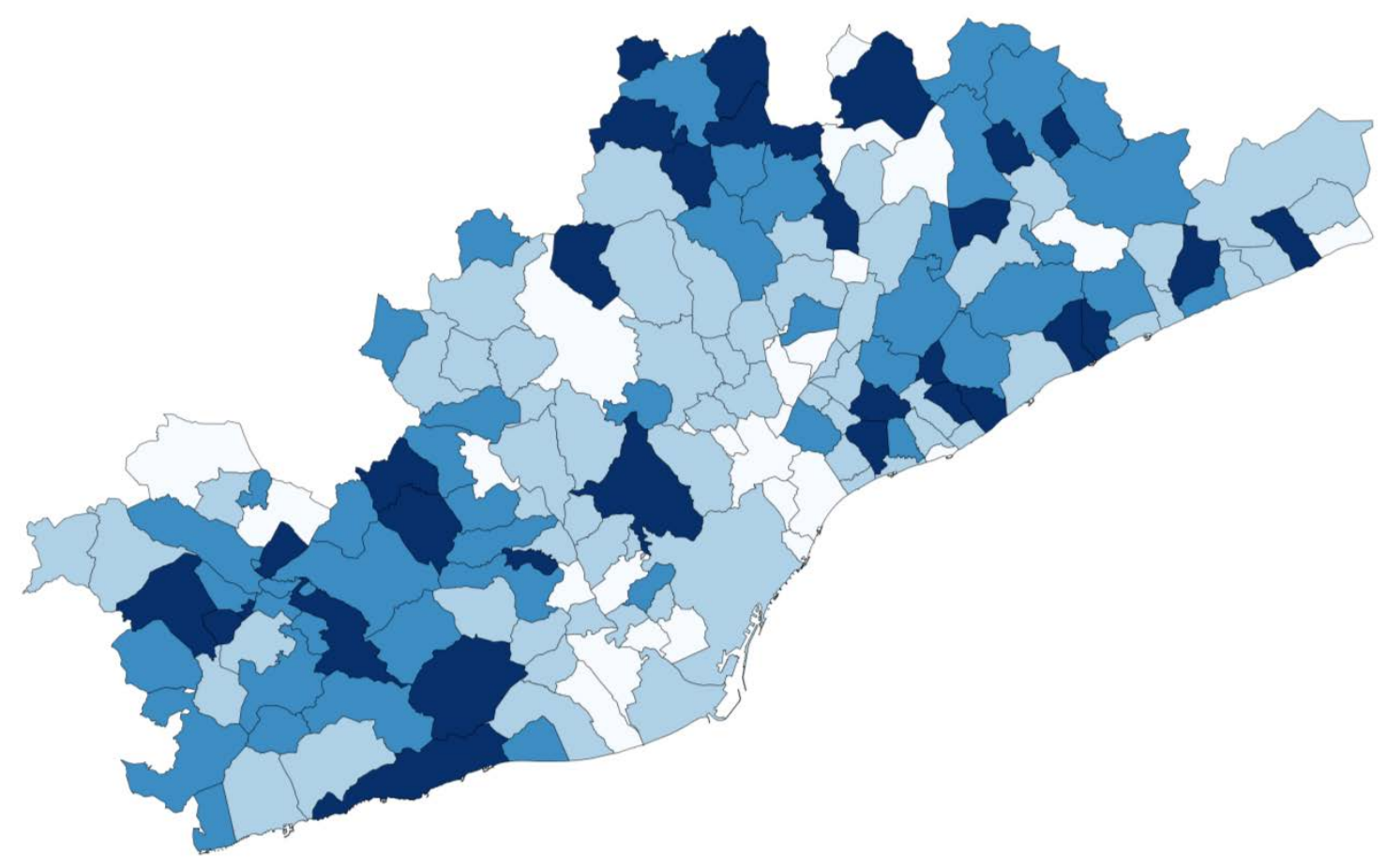

Fuente: elaboración a partir de las fuentes citadas

A pesar de que las alteraciones no son excesivamente marcadas, sí son claramente más coherentes con un consumo doméstico de electricidad ajustado a la realidad. Así, la diferencia entre los consumos por habitante más altos y más bajos se ha reducido, al haber asignado más población a los municipios menos poblados pero con una alta proporción de residencias secundarias, y al haber reducido la de aquellos que se encontraban en la situación inversa.

En cualquier caso, el análisis muestra diferencias claras en el consumo doméstico de electricidad de los municipios metropolitanos. Como ha sido apuntado al principio, son muchas las variables que tienen una incidencia en esta diversidad, pero entre ellas cabe considerar también la tipología de los tejidos residenciales. El siguiente apartado trata de identificar estas tipologías para, finalmente, evaluar la relación entre tipología residencial y consumo doméstico de electricidad.

Y para la población final de cada municipio (PFm):

$$
P F_{m}=\left(P_{m}+\Delta P_{m}\right) * \frac{\sum P_{m}}{\sum P_{m+} \sum \Delta P_{m}}
$$




\subsection{Identifica ción de las tipologías urbanas}

La base para la identificación de las tipologías urbanas que ha servido para distinguir los consumos domésticos de electricidad ha sido el Mapa de cubiertas del suelo de Catalunya del Centre d'Investigació Ecològica i Aplicacions Forestals (CREAF). La $4^{\text {a }}$ edición del Mapa elaborado por el CREAF, correspondiente al año 2009, etiqueta su base de polígonos (279448 para la región metropolitana de Barcelona) a partir de cuatro campos (tipo de cubiertas del suelo compuesta, tipo de edificación, tipo de cubiertas del suelo simple y cubierta en construcción) que dan como resultado 411 categorías. ${ }^{23}$ De estas categorías se han seleccionado únicamente seis, aquellas que corresponden plenamente y de manera inequívoca a tejidos residenciales: "Centro urbano", "Ensanche", "Colonias y núcleos aislados", "Viviendas unifamiliares", "Casas aisladas" y "Urbanizaciones". El resto de cubiertas se han descartado, incluidas aquellas que puedan ser consideradas propias de tejidos urbanos (y que, incluso, tengan régimen de urbano en las clasificaciones urbanísticas). Se trata de categorías tales como los parques urbanos, los equipamientos educativos o los sanitarios $y$, por supuesto, las cubiertas correspondientes a actividad industrial o terciaria. Las categorías seleccionadas son, por lo tanto, superficies residenciales netas (o prácticamente netas, porque sí incorporan, por ejemplo, el viario local). Estas seis categorías residenciales ocupan 39549 hectáreas, es decir, un 12,2\% de las 323600 hectáreas de la región metropolitana de Barcelona.

Esta clasificación ha estado sujeta, sin embargo, a una posterior revisión para adaptarla a cuatro categorías de trabajo básicas en función de los objetivos de la investigación: "Bloques contiguos", "Bloques abiertos", "Casas Adosadas" y "Casas aisladas". ${ }^{24}$ Estas cuatro categorías, representadas en la Figura 3, permiten simplificar la clasificación anterior manteniendo una diferenciación básica en función de las variables que se han considerado representativas, tanto en cuanto a la tipología residencial (vivienda plurifamiliar las dos primeras y unifamiliar las dos últimas) como, de manera aproximada, su densidad. La Tabla 2 muestra el detalle de la reasignación de los polígonos.

La reclasificación ha permitido simplificar las tipologías del suelo, pero aun así, es difícil encontrar algún municipio en que el suelo residencial corresponda íntegramente a una única tipología. Y, sin

23 Las bases cartográficas del Mapa de cobertes del sòl de Catalunya se pueden descargar en formato vectorial en el portal web del CREAF: http://www.creaf.uab.es/mcsc/descriptiu.htm

24 La revisión se ha realizado visualmente a partir de la superposición del mapa de cubiertas del suelo con la ortofotografía de Cataluña 1:5000 entre los años 2011 y 2013 disponible a través de la conexión WMS del Institut Cartogràfic i Geològic de Catalunya. 
embargo, esta calificación a nivel de municipio es necesaria, ya que los datos disponibles sobre consumo doméstico de electricidad se encuentran agrupados a nivel municipal. ${ }^{25}$

Por su proceso de formación a lo largo de la historia, prácticamente todos los términos municipales muestran diversas tipologías urbanas, correspondientes a las características de desarrollo predominantes en cada momento. En este sentido, los municipios difícilmente pueden ser calificados a partir de una única tipología sino, más bien, a partir de aquella claramente predominante. Por este motivo, se ha establecido un umbral mínimo a partir del cual un municipio queda asignado a una determinada tipología: el 75 \%. Así, todos los municipios con un mínimo del $75 \%$ de su suelo residencial correspondiente a una única tipología han sido asignados a esa tipología.

\section{Figura 3. Tipologías de suelo residencial consideradas a partir de la reclasificación del Mapa de cobertes}

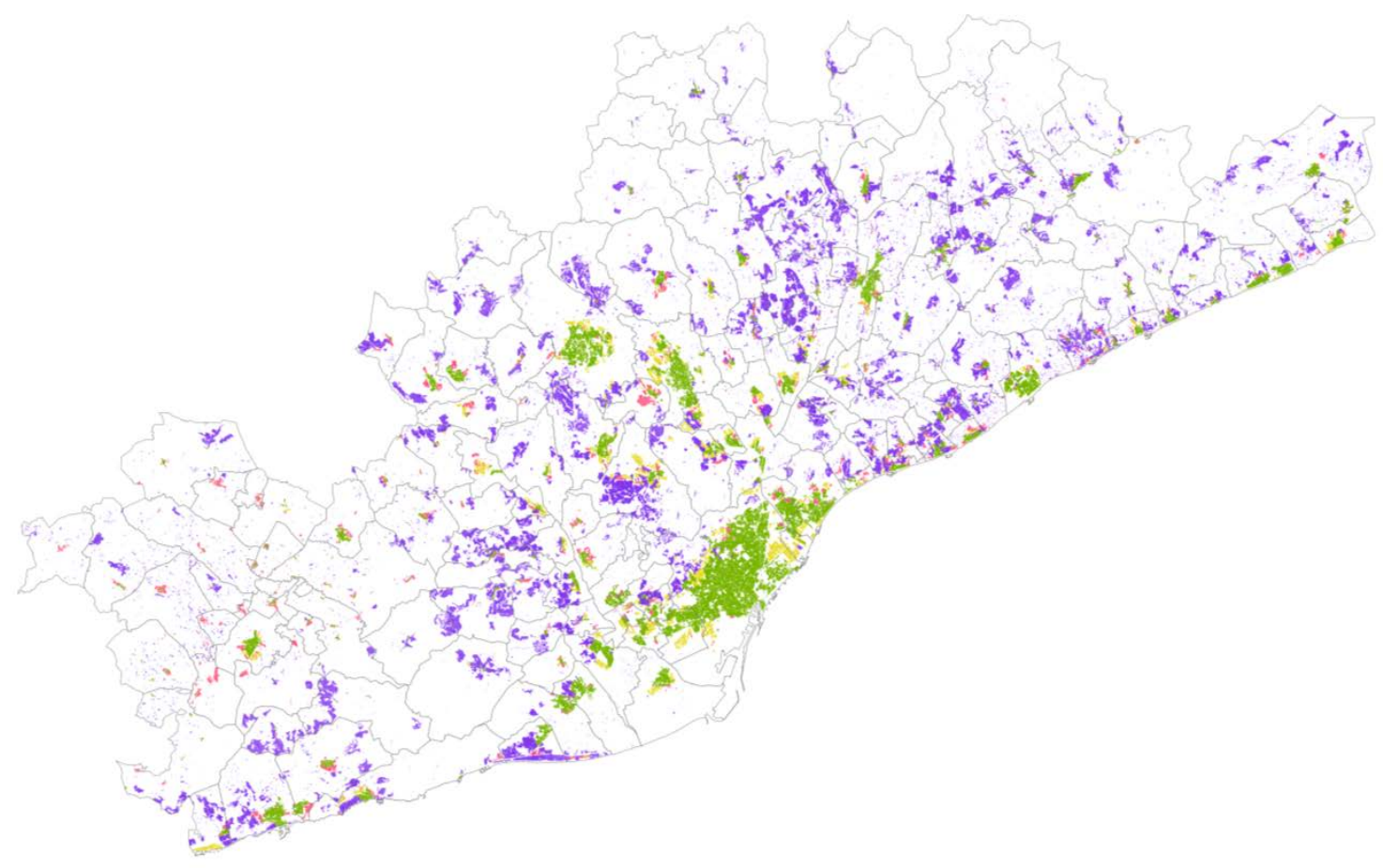

Fuente: elaboración a partir de las fuentes citadas

25 El análisis más apropiado requeriría, evidentemente, unas unidades territoriales de referencia para la información estadística mucho menores, más aún si se considera el nivel de detalle de la información referente a los tipos de suelo. La reserva en este sentido tanto de las empresas comercializadoras y distribuidoras de electricidad como del propio Institut Català de l'Energia para no violentar el secreto estadístico ha hecho imposible la obtención de estos datos para unidades territoriales más pequeñas y obliga a realizar el análisis a nivel municipal. 
Tabla 2. Reclasificación de les categorías de suelo residencial del Mapa de cobertes de/ sò/ 2009

\begin{tabular}{|l|c|c|c|c|c|}
\hline & $\begin{array}{c}\text { Bloques } \\
\text { contiquos }\end{array}$ & $\begin{array}{c}\text { Bloques } \\
\text { abiertos }\end{array}$ & $\begin{array}{c}\text { Cases en } \\
\text { hilera }\end{array}$ & $\begin{array}{c}\text { Cases } \\
\text { aisladas }\end{array}$ & Total \\
\hline Centro urbano & 1111 & 0 & 1 & 3 & 1115 \\
\hline Ensanche & 4948 & 3.333 & 392 & 508 & 9181 \\
\hline Colonias y núcleos aislados & 0 & 0 & 390 & 0 & 390 \\
\hline Viviendas unifamiliares & 596 & 45 & 2883 & 9767 & 13291 \\
\hline Urbanizaciones & 0 & 0 & 1 & 19288 & 19289 \\
\hline Casas aisladas & 0 & 4 & 0 & 14429 & 14433 \\
\hline Total & 6655 & 3382 & 3667 & 43995 & 57699 \\
\hline
\end{tabular}

Fuente: elaboración propia a partir de las bases vectoriales del Mapa de cobertes del sòl 2009 del CREAF

Esta operación tiene la ventaja de simplificar la adscripción de municipios a una tipología urbana concreta, pero presenta un doble inconveniente. Por una parte, considera como correspondientes a una determinada tipología tejidos residenciales de características diferentes. A pesar de que representen una proporción minoritaria, es evidente que esta inclusión de tejidos diferentes al predominante distorsionará en parte los resultados. Por otra parte, el hecho de establecer un umbral mínimo descarta muchos municipios el suelo residencial de los cuales no únicamente es heterogéneo, sino que lo es en una proporción más o menos equilibrada, de manera que ninguna tipología predomina claramente. Como resultado, tal como puede apreciarse en la Figura 4, tan sólo 80 de los 164 municipios metropolitanos han podido ser considerados en el análisis. Cabe añadir que los municipios seleccionados no representan homogéneamente las diversas categorías consideradas sino que la mayoría de ellos corresponden a casas aisladas, mientras que sólo cuatro son de bloques contiguos, dos de casas en hilera y un de bloques abiertos.

A pesar de estas dos limitaciones, la simplificación descrita es necesaria para poder realizar los cruces con los datos de consumo de electricidad en el formato del que se dispone. 


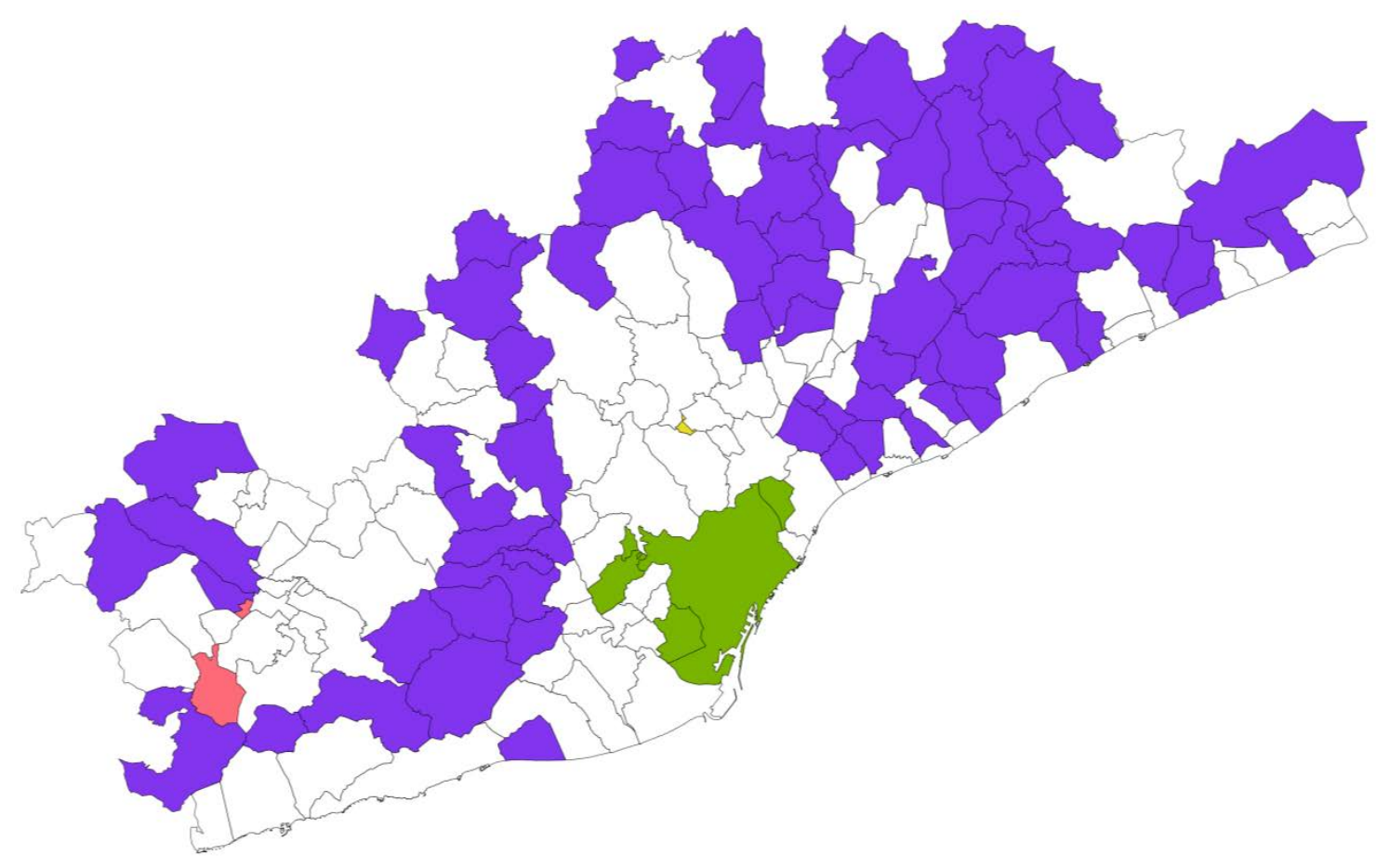

Fuente: elaboración a partir de las fuentes citadas

\subsection{Consumo doméstico de electricidad según la tipología residencial}

El cruce de los datos de consumo doméstico de electricidad por habitante real con la tipología urbana de los municipios seleccionados muestra una relación clara entre ambas variables. Así, entre los 80 municipios de la región metropolitana de Barcelona considerados, aquellos que cuentan con una tipología residencial claramente predominante de bloques contiguos (Santa Coloma de Gramenet, Hospitalet de Llobregat, Sant Feliu de Llobregat y Barcelona) y el único representante de bloques abiertos (Badía de Vallés) tienen los consumos domésticos de electricidad por habitante más bajos, inferiores siempre a los $1500 \mathrm{kWh} / \mathrm{hab}$ y en ocasiones a los $1000 \mathrm{kWh} / \mathrm{hab} .{ }^{26} \mathrm{En}$ cambio, los municipios donde las tipologías de casas aisladas son claramente predominantes tienden a mostrar los consumos más elevados que, en algunos casos (Matadepera, Cabrils, Gallifa, Alella, Vallromanes, Tagamanent, Sant Quirze Safaja, Castellcir, San Cebrià de Vallalta, Campins, Sant Vicenç de Montalt), superan los 2000 kWh/hab, es decir, el doble de los municipios con un consumo menor.

26 Es incluso posible que el consumo de Barcelona esté alterado por la existencia de actividades económicas, básicamente terciarias, en muchos inmuebles destinados principalmente a vivienda, elemento que la estadística puede no recoger con precisión. 
La Figura 5 muestra de manera sintética estos resultados poniéndolos en relación con la densidad media de población por hectárea de suelo residencial para cada una de las tipologías analizadas. Como se puede comprobar, las tipologías menos densas, es decir, las correspondientes a las casas en hilera $y$, sobre todo, a las casas aisladas, tienen un consumo medio de electricidad en los hogares (1626,3 kWh/hab y 1672,3 kWh/hab respectivamente) muy superior a los bloques, ya sean estos contiguos o abiertos (1185,6 kWh./hab y 1095,4 kWh/hab respectivamente).

Figura 5. Consumo doméstico medio de electricidad de las diversas tipologías residenciales

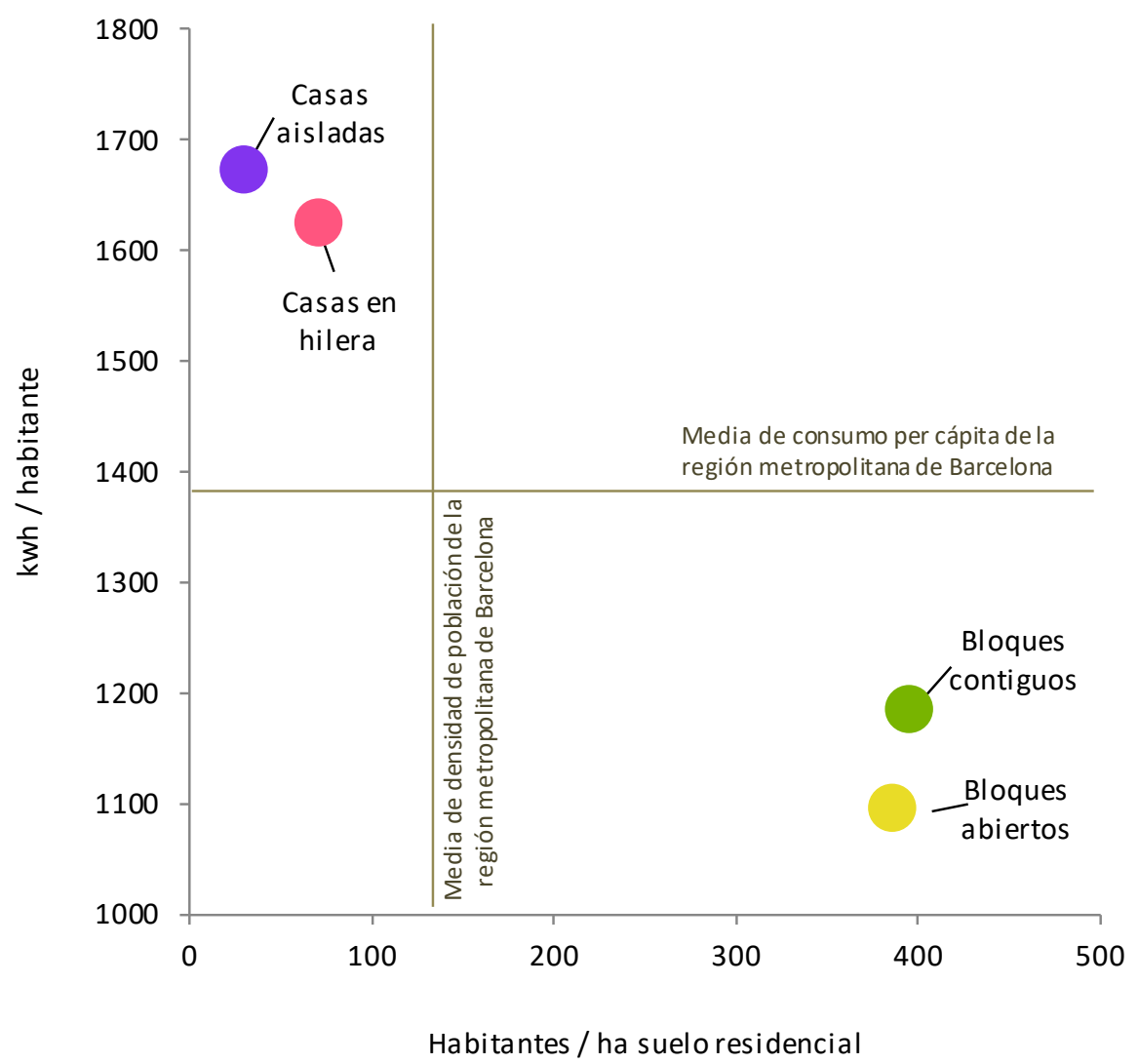

Fuente: elaboración a partir de las fuentes citadas

La relación entre tipología urbana y consumo doméstico de electricidad es, de este modo, evidente a la luz de los resultados obtenidos. Ahora bien, la disponibilidad y las características de los datos con que se ha trabajado no permiten determinar en qué medida estas diferencias en el consumo deben ser atribuidas a la tipología urbana y qué incidencia tendrían otras variables. En este sentido, otros dos factores parecen, a priori, estrechamente relacionadas con el consumo de electricidad en los hogares: la existencia de otros suministros energéticos alternativos a la electricidad y el nivel de ingresos de las unidades familiares. Una primera aproximación permite constatar cómo, ciertamente, existe una relación también con estas variables. Pero hace posible observar también cómo la tipología urbana continúa manteniendo una incidencia más allá del atribuible al uso de otras fuentes energéticas o el nivel de renta. 
En cuanto a la existencia de suministros alternativos a la electricidad en los hogares, la fuente que tiene una mayor importancia en las áreas urbanas es el gas natural, ya sea para cocinar como, sobre todo, para calefacción y agua caliente. Al incorporar los datos de consumo de gas natural en los hogares de los municipios metropolitanos se observa como aquellos con tipologías residenciales más densas muestran un consumo de gas natural muy superior a la media. ${ }^{27}$ De este modo, el consumo agregado de las dos fuentes (electricidad y gas natural) desplaza estos municipios desde las posiciones de consumo más bajas a posiciones intermedias. Estos resultados podrían llevar a concluir que estos municipios no presentaban un consumo doméstico de electricidad menor que los de los municipios con tejidos menos densos porque consumieran menos energía sino porque reemplazaban la energía eléctrica por otras fuentes.

Ahora bien, esta conclusión no se corresponde con la realidad por tres motivos fundamentalmente. El primero es que, a pesar de desplazarse hacia posiciones intermedias, los municipios con tipologías más densas siguen situándose de manera mayoritaria por debajo de la media.

El segundo motivo está relacionado con la disponibilidad de gas natural. Como es sabido, a diferencia de la electricidad o de otros combustibles, el gas natural no llega a todos los municipios sino únicamente a aquellos que disponen de infraestructura de canalización, la cual tiende a concentrarse en las áreas urbanas, es decir, allí donde las tipologías más densas son predominantes. Por lo tanto, la consideración del consumo agregado de gas natural y electricidad distorsiona también los resultados reales al incorporar un suministro alternativo existente únicamente en determinados municipios. De hecho, si se obvian los municipios que no disponen de oferta de gas natural, aquellos donde las tipologías de bloques son predominantes vuelven a ocupar las bandas de consumo más bajas, incluso sin considerar, como se ha dicho, los combustibles alternativos frecuentemente utilizados en las áreas menos densas y poco o nada utilizados en las áreas urbanas.

El tercer motivo, complementario del anterior, tiene que ver con el resto de suministros que pueden sustituir la electricidad y el gas natural en las aplicaciones domésticas: el gasóleo C, los gases licuados del petróleo (tanto butano como propano) e incluso la biomasa (tanto la tradicional, en forma de leña, como a partir de formas más modernas de utilización, como pueden ser los pellets) o instalaciones de autogeneración en los propios edificios. Estas fuentes alternativas permiten reducir el consumo de electricidad tanto para calefacción como para otras aplicaciones finales. Ahora bien, como se ha dicho, no existen datos territorializados de su consumo, en la mayoría de casos por la imposibilidad misma de asignar la localización del consumidor final a escala local. El

27 Como en el caso de los datos de electricidad, los datos sobre consumo doméstico de gas natural de los municipios de la región metropolitana de Barcelona fueron suministrados por el Institut Català de l'Energia (ICAEN). 
principal elemento distorsionador que introduce este elemento es que el uso de estos suministros alternativos tiende a concentrarse en las áreas coincidentes con las tipologías menos densas, y, por tanto, el consumo doméstico total de estos municipios se encuentra subrepresentado.

Es decir, los resultados no reflejan el consumo total de energía en los hogares correspondientes a las tipologías residenciales más densas, en los que el gas natural sustituye en gran medida la electricidad; pero el posible efecto distorsionador de este factor sobre el consumo de electricidad queda compensado por el hecho de no contabilizar tampoco los suministros alternativos más habituales en las áreas donde los tejidos de baja densidad son predominantes.

En cuanto al nivel de renta, su relación con el consumo de energía es conocida: según la Encuesta de Presupuestos Familiares del INE, en el año 2014 el gasto medio en electricidad, gas y otros combustibles de los hogares españoles con unos ingresos mensuales más bajos (inferior a 500 euros) era de 669,56 euros al año, gasto que aumentaba progresivamente a medida que se incrementaban los ingresos hasta los 1933,46 euros anuales gastados en los hogares con más de 5000 euros de ingresos mensuales, es decir, casi tres veces más. ${ }^{28}$ Por otra parte, el mapa del nivel de ingresos por habitante a nivel municipal también permite observar una relación entre los municipios donde las rentas son más elevadas y aquellos donde predominan los tejidos residenciales de densidades más bajas. ${ }^{29}$

La coexistencia de las dos relaciones podría cuestionar la hipótesis de que un mayor consumo doméstico de electricidad es debido a la tipología urbana, ya que correspondería mayoritariamente a la disponibilidad de renta. Ahora bien, el cruce de estas dos variables permite constatar la incidencia de la tipología urbana en el consumo.

Así, como muestra la Tabla 3, de los 114 municipios metropolitanos considerados, aquellos con una renta más alta llegan a consumir, ciertamente, hasta el doble de los que tienen una renta más baja. Lo que es interesante destacar, sin embargo, es que para cada intervalo de renta, los municipios donde predominan los tejidos de alta densidad tienen un consumo doméstico de electricidad menor. Y, lo que resulta más significativo: incluso los municipios de densidades altas con el nivel de renta más elevado tienen un consumo de electricidad menor que cualquiera de las categorías de los municipios de densidades bajas, incluidos los de renta más baja. Existe, sin duda, una relación entre nivel de renta y consumo doméstico de electricidad, pero la importancia de la tipología urbana resulta aún más significativa.

28 Instituto Nacional de Estadística (INE). Encuesta de presupuestos familiares. Recuperado de http://www.ine.es/

29 Como variable representativa de la renta se ha utilizado el importe en euros de la "Base imponible por declarante del Impuesto de la Renta de las Personas Físicas" correspondiente al ejercicio 2012. Institut d'Estadística de Catalunya (Idescat). Recuperado de http://www.idescat.cat/ 
Tabla 3. Consumo doméstico de electricidad de los municipios metropolitanos en función del nivel de renta y la tipología urbana predominante, kWh/hab

\begin{tabular}{|c|c|c|c|}
\hline \multirow{4}{*}{$\begin{array}{c}\text { Nivel de } \\
\text { renta }\end{array}$} & $\begin{array}{c}\text { Muy alta } \\
>1,5 \bar{x}\end{array}$ & $\begin{array}{c}\text { (7 municipios) } \\
1.978,44\end{array}$ & (0 municipios) \\
\hline & $\begin{array}{l}\text { Alta } \\
\bar{x}-1,5 \bar{x}\end{array}$ & $\begin{array}{c}\text { (44 municipios) } \\
1.658,74\end{array}$ & $\begin{array}{c}\text { (3 municipios) } \\
1.335,57\end{array}$ \\
\hline & $\begin{array}{c}\text { Baja } \\
0,8 \bar{x}-\bar{x}\end{array}$ & $\begin{array}{c}\text { (41 municipios) } \\
1.545,24\end{array}$ & $\begin{array}{c}\text { (12 municipios) } \\
1.240,18\end{array}$ \\
\hline & $\begin{array}{c}\text { Muy baja } \\
<0,8 \bar{x}\end{array}$ & $\begin{array}{c}\text { (4 municipios) } \\
1.507,33\end{array}$ & $\begin{array}{c}\text { (3 municipios) } \\
1.080,38\end{array}$ \\
\hline & & $\begin{array}{c}\text { Baja densidad } \\
\text { (>70\% del suelo residencial } \\
\text { correspondiente a casas } \\
\text { aisladas o casas en hilera) }\end{array}$ & $\begin{array}{c}\text { Alta densidad } \\
\text { ( }>70 \% \text { de suelo residencial } \\
\text { correspondiente a bloques } \\
\text { abiertos o bloques contiguos) }\end{array}$ \\
\hline & & \multicolumn{2}{|c|}{ Tipología urbana } \\
\hline
\end{tabular}

Fuente: elaboración a partir de de los propios resultados

y Encuesta de Presupuestos Familiares del INE

\section{Conclusiones}

En el presente trabajo se ha ensayado un análisis de los estudios sobre la relación entre forma urbana y consumo de electricidad existentes, una descripción del proceso de poblamiento y ocupación del suelo en la región metropolitana de Barcelona en los últimos años así como el desarrollo y aplicación de una metodología para estimar dichas relaciones sobre este ámbito. Los resultados alcanzados permiten obtener algunas conclusiones destacadas:

- El conocimiento sobre el consumo doméstico de electricidad según la tipología urbana se ve limitado por dos carencias básicas en los datos disponibles para la región metropolitana de Barcelona: por un lado, la dificultad de acceder a los datos de consumo eléctrico con un nivel de desagregación territorial inferior al municipio; por otro, la carencia de datos referentes a suministros alternativos a la electricidad más allá del gas natural, como son el butano, el propano el gasóleo C o la biomasa, incluso a nivel municipal. La doble limitación en la disponibilidad de información obliga a la elaboración de metodologías complejas para la estimación del consumo doméstico de electricidad, con el consiguiente sesgo que esta estimación puede conllevar.

- Seguramente esta falta de datos exhaustivos sobre consumos energéticos y con el nivel de desagregación territorial necesario es responsable en buena parte a la relativa escasez de 
análisis sobre la relación entre consumo doméstico de electricidad y tipología urbana no sólo en la región metropolitana de Barcelona sino prácticamente en todas las áreas urbanas.

- A pesar de estas limitaciones, las estimaciones realizadas para la región metropolitana de Barcelona muestran una clara relación entre el consumo doméstico de electricidad y la tipología urbana. De este modo, el surgimiento y posterior generalización de unas pautas de ocupación del suelo basadas en la dispersión, la baja densidad y la especialización residencial añade a impactos ya conocidos tales como mayor consumo de suelo, la utilización preferente del vehículo privado para los desplazamientos cotidianos o el mayor consumo de agua, la existencia de un mayor consumo doméstico de electricidad.

- Así, aquellos municipios de la región metropolitana de Barcelona donde predominan las tipologías urbanas densas y compactas, las correspondientes a bloques contiguos y bloques abiertos, muestran unos consumos domésticos de electricidad por habitante no sólo inferiores a la media metropolitana, sino situados en los tramos más bajos posibles de consumo: en Sant Feliu de Llobregat el consumo doméstico de electricidad por habitante real rebasó de poco los 1200 kWh en 2012, mientras en Hospitalet de Llobregat o Badia del Vallès se situaba en torno a los 1100 kWh y en Santa Coloma era inferior a 1000 kWh. Por el contrario, en aquellos municipios con claro predominio de las tipologías residenciales dispersas y de menor densidad, las correspondientes a casas aisladas o casas en hilera, el consumo puede llegar a ser el doble: Matadepera, Cabrils, Alella, Vallromanes, Sant Quirze Safaja, Sant Cebrià de Vallalta o Sant Vicenç de Montalt muestran consumos por habitante real siempre superiores a los $2000 \mathrm{kWh}$ al año.

- Si bien los resultados obtenidos pueden quedar en parte distorsionados por la consideración exclusiva de un suministro energético (la electricidad) y la falta de datos relativos a suministros alternativos (gas natural, gases licuados del petróleo, gasóleo C o biomasa) u obedecer a otras causas diferentes a la tipología urbana (como el nivel de renta), la incorporación al análisis de estas variables muestra que la relación entre consumo doméstico de electricidad y tipología urbana es estrecha.

A la espera de disponer de un nivel de desagregación territorial de la información superior a la actual o de contar con esta misma información para otros ámbitos urbanos, el análisis realizado muestra, en cualquier caso, como el modelo disperso y de baja densidad de ocupación del suelo añade a sus consecuencias negativas un mayor consumo doméstico de electricidad por habitante. 


\section{Bibliografía}

Akbari, H., y Konopacki, S. (2005). Calculating energy-saving potentials of heat-island reduction strategies. Energy Policy, 33, 721-756.

Alexander, C., Ishikawa, S., y Silverstein, M. (1977). A Pattern Language: Towns, Buildings, Construction. Nueva York: Oxford University Press.

Anderson, W. P, Kanaroglou, P. S., y Miller, E. J. (1996). Urban Form, Energy and the Environment: A Review of Issues, Evidence and Policy. Urban Studies, 33(1), 7-35.

Arango, J. (2007). Les primeres migracions del segle XX a Catalunya. En A. Cabré (Coord.), Immigració. Les onades immigratòries en la Catalunya contemporània. Barcelona: Fundació Lluís Carulla.

Arroyo, M. (2003). Technical Networks and Urban Territory: A Survey of the Literature in Spain. En M. Hard y T. Misa (Eds.), The Urban Machine: recent Literature on European Cities in the 20th Century (pp. 1-16). Recuperado de http://www.tc.umn.edu/ rmisa/toe20/urbanmachine/complete-pwd.pdf

Arroyo, M., y Capel, H. (2002). Una bibliografía sobre la tecnología urbana en las ciudades españolas (siglos XIX y XX). Biblio 3W, VII(375).

Arroyo, M., y Cardoso de Matos, A. (2009). La modernización de dos ciudades: las redes de gas de Barcelona y Lisboa (siglos XIX y XX). Scripta Nova, XIII, 296(6).

Bartolome, I. (2007). La industria eléctrica en España (1890-1936). Estudios de Historia Económica, n. ${ }^{\circ}$ 50. Madrid: Banco de España.

Bertoldi, P., Hirl, B., y Labanca, N. (2012). Energy Efficiency Status Report 2012. Electricity Consumption and Efficiency Trends in the EU-27. European Commission, Joint Research Centre y Institute for Energy and Transport.

Cabré, A. (1999). El sistema català de reproducció. Barcelona: Editorial Proa.

Cabré, A. (2007). Les onades migratòries en el sistema català de reproducció. En A. Cabré (Coord.), Immigració. Les onades immigratòries en la Catalunya contemporània (pp. 11-17). Barcelona: Fundació Lluís Carulla.

Cabré, A. y Pujadas, I. (1989). La població: immigració i explosió demográfica. En J. Nadal et al. (Dirs.), Història econòmica de la Catalunya contemporània (pp. pp.11-128). Barcelona: Enciclopèdia Catalana.

Camagni, R., Gibelli, C., y Rigamonti, P. (2002). I costi collettivi della città dispersa. Alinea Editrice. 
Capel, H. (Dir.) (1994). Les tres xemeneies. Implantació industrial, canvi tecnològic i transformació d'un espai urbà barceloní (3v). Barcelona: Fecsa.

Carreras, J. M. (2002). La redistribució de la ciutat al territori de la regió metropolitana de Barcelona. En Papers. Regió metropolitana de Barcelona, n. ${ }^{\circ}$ 36. Barcelona: Institut d'Estudis Regionals i Metropolitans de Barcelona.

Centre d'Etudes et de Recherches Economiques sur l'Energie. Recuperado de http://www.ceren.fr/stats/stat1.aspx

Centre de Recerca Ecològica i Aplicacions Forestals (CREAF). Mapa de Cobertes del Sòl de Catalunya. Recuperado de http://www.creaf.uab.es/mcsc/descriptiu.htm

Destatis Statistisches Bundesamt. Recuperado de https://www.destatis.de

Direcció de Serveis Ambientals de L'amb y Barcelona Regional (2014). Balanços energètics dels municipis metropolitans. Barcelona: AMB.

Feria, J. M. (2011). Ciudad y territorio: nuevas dinámicas espaciales. En I. Pujades et al. (Eds.), Población y espacios urbanos. XII Congreso de Población Española. Barcelona.

Ferrer, A. (1996). Els polígons a Barcelona. Barcelona: Edicions UPC.

Font, A., Llop, C., y Vilanova, J. M. (1999). La construcció del territori metropolità. Morfogènesi de la regió urbana de Barcelona. Barcelona: MMAMB.

Font, A., y Carreras, J. M. (dirs.) (2006). Transformacions urbanitzadores 1977-2000. Àrea metropolitana i regió urbana de Barcelona. Barcelona: Mancomunitat de Municipis de I'Àrea Metropolitana de Barcelona.

Goerlich, F. J., y Mas, M. (2006). La localización de la población española sobre el territorio. Un siglo de cambios. Un estudio basado en series homogéneas (1900-2001). Bilbao: Fundación BBVA.

Heiple, S., y Sailor, D. J. (2008). Using building energy simulation and geospatial modelling techniques to determine high resolution building sector energy consumption profiles. Energy and Buildings, 40, 1426-1436.

Howard, B. et al. (2012). Spatial distribution of urban building energy consumption by end use. Energy and Buildings, 45, 141-151.

Indovina, F. (Coord.) (2007). La ciudad de baja densidad. Lógicas, gestión y contención. Barcelona: Diputació de Barcelona.

Institut Cartogràfic de Catalunya. Recuperado de http://www.icc.cat/

Institut Català de l'Energia (ICAEN). Recuperado de http://icaen.gencat.cat/ca/index.html 
Institut d'Estadística de Catalunya (Idescat). Recuperado de http://www.idescat.cat/

Instituto Nacional de Estadística (INE). Recuperado de http://www.ine.es/

Instituto para la Diversificación y Ahorro de la Energía. Recuperado de

http://www.idae.es/index.php

Instituto para la Diversificación y el Ahorro de la Energía (2011). Análisis del consumo energético del sector residencial en España. Proyecto SECH-SPAHOUSEC. Recuperado de http://www.idae.es/uploads/documentos/documentos_informe_spahousec_acc_f68291a3.pdf Lariviere, I., y Lafrance, G. (1999). Modelling the electricity consumption of cities: effect of urban density. Energy Economics, 21, 53-66.

Lewis, J. O., Ní Hógáin, S., y Borghi, A. (2013). Building energy efficiency in European cities. European Union: Urbact.

López, J. (2007). Les migracions residencials extramunicipals a la regió metropolitana de Barcelona en el Període 2000-2005 (Working Paper). Barcelona: Institut d'Estudis Territorials.

López, J. (2011). La regione metropolitana di Barcellona: elementi di diagnosi per il Piano Territoriale. En A. Acierno y A. Mazza, A. (Eds.), Governare la metropoli. Il Piano Terrritoriale Metropolitano di Barcelona (pp. 53-68). Napoli: Universiłà degli Studi di Napoli Federico II i Edizioni Scientifiche Italiane.

López, J. (2015). The Spatial Plan of the Metropolitan Region of Barcelona. En A. Lai y L. Ming. (Eds.), City and Countryside (pp. 120-139). Harbin: Harbin Institute of Technology Press.

Madlener, R., y Sunak, Y. (2011). Impacts of urbanization on urban structures and energy demand: What can we learn for urban energy planning and urbanization management? Sustainable Cities and Society, 1, 45-53.

Mapa Urbanístic de Catalunya. Recuperado de http://territori.gencat.cat/ca/06_territori_i_urbanisme/urbanisme/mapa_urbanistic_de_catalunya/ dades_basiques_municipals_i_comarcals_intern/

March, L., y Martin, L. (1975). Urban Space and Structures. Cambridge: Cambridge University Press.

Martorell, V., Florensa, A., y Martorell, V. (1970). Historia del Urbanismo en Barcelona. Del Plan Cerdà al Área Metropolitana. Barcelona: Editorial Labor.

Mindali, O., Raveh, A., y Salomon, I. (2004). Urban density and energy consumption: a new look at old statistics». Transportation Research, Part A 38, 143-162. 
Muñoz, F. (2005). La producció residencial de baixa densitat. Elements de debat territorial, $n .^{\circ}$ 21. Barcelona: Diputació de Barcelona.

Muñoz, F. (Ed.) (2011). Estrategias para la ciudad de baja densidad: de la contención a la gestión. Barcelona: Diputació de Barcelona.

Nadal, J. (1995). La población española (siglos XVI a XX), Barcelona: Ariel.

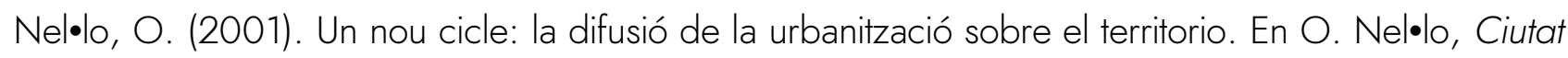
de ciutats. Barcelona: Empúries.

NEL•LO, O. (2004). ¿Cambio de siglo, cambio de ciclo? Las grandes ciudades españolas en el umbral del siglo XXI. Ciudad y territorio. Estudios territoriales, XXXVI, 141-142.

NEL•LO, O. (2007). Contra la dispersión, intensidad. Contra la segregación ciudad. En F. Indovina (Coord.), La ciudad de baja densidad. Lógicas, gestión y contención. Barcelona: Diputació de Barcelona.

NEL•LO, O. (2011a). Estrategias para la contención y gestión de las urbanizaciones de baja densidad en Cataluña. Ciudad y territorio. Estudios territoriales, XLIII (167).

NEL•LO, O. (2011b). Las urbanizaciones con déficits urbanísticos: de la utopía a la gestión. En F. Muñoz (Ed.), Estrategias para la ciudad de baja densidad: de la contención a la gestión. Barcelona: Diputació de Barcelona.

Norman, J., Mac Lean, H. L., y Kennedy, C. A. (2006). Comparing High and Low Residential Density: Life-Cycle Analysis of Energy Use and Greenhouse Gas Emissions. Journal of Urban Planning and Development, 132(1), 10-21.

Pascual, A., y Cardelús, J. (1998). Migracions a Catalunya: entre la mobilitat i l'assentament. En S. Giner (Dir.) La societat catalane (pp. 189-199). Barcelona: Generalitat de Catalunya.

Pèrez-Lombard, L., Ortiz, J., y Pout, C. (2008). A review on buildings energy consumption information. Energy and Buildings, 40, 394-398.

Pla territorial metropolità de Barcelona Recuperado de http://territori.gencat.cat/ca/01_departament/05_plans/01_planificacio_territorial/ plans_territorials_nou/territorials_parcials/ptp_metropolita_de_barcelona/

Pujadas, I., y Mendizábal, E. (1992). La població de Catalunya en el període 1975-1986: de I'explosió demogràfica al creixement zero. Barcelona: Generalitat de Catalunya, Departament de Política Territorial i Obres Públiques.

Ratti, C., Baker, N., y Steemers, K. (2005). Energy consumption and urban texture. Energy and Buildings, 37, 762-776. 
Rueda, S. (2002): Els costos ambientals dels models urbans dispersos. En Papers. Regió Metropolitana de Barcelona, n. ${ }^{\circ}$ 36. Barcelona: Institut d'Estudis Regionals i Metroplitans de Barcelona.

Salat, S., y Bourdic, L. (2012). Urban Complexity, Efficiency and Resilience. En Morvaj, Z. (ed.), Energy Efficiency. A Bridge to Low Carbon Economy. InTech. doi: 10.5772/38599.

Saurí, D. (2005). Els usos de l'aigua a Catalunya. Revista Medi Ambient. Teconologia i Cultura, $36,22-29$.

Saurí, D. (2011). Urbanisme i nova cultura de l'aigua: una relació necessària. En Cap a un habitat(ge) sostenible. Informes del CADS. Barcelona: Generalitat de Catalunya, Departament de Presidència.

Serra, J. (1997). Migracions metropolitanes i desconcentració demogràfica. Revista econòmica de Catalunya, 33.

Serra, J. (2003). El territori metropolità de Barcelona. Dades bàsiques, evolució recent $i$ perspectives. Barcelona: Mancomunitat de Municipis de l'Àrea Metropolitana de Barcelona.

Servei D'estudis Territorials de la MMAMB (1994). Dinàmiques metropolitanes a l'àrea i regió de Barcelona. Barcelona, Mancomunitat de Municipis de l'Àrea Metropolitana de Barcelona.

Shashua-Bar, L., y Hoffman, M. E. (2000). Vegetation as a climatic component in the design of an urban street. An empirical model for predicting the cooling effect of urban green areas with trees. Energy and Buildings, 31, 221-235.

Smith, L. C. (2011). The World in 2050: Four Forces Shaping Civilization's Northern Future. Londres: Profile books Ltd.

Solans, J. A. (2002). L'ocupació de sòl en el sistema metropolità central durant el període 19801998. Papers, 36, 51-72.

Statistics Norway. Energy consumption in households. Recuperado de http://www.ssb.no/en/energi-og-industri/statistikker/husenergi

Steemers, K. (2003). Energy and the city: density, buildings and transport. Energy and Buildings, 35, 3-14.

Tello, E. (2005). L'aigua: un dret o un servei? Revista Medi Ambient. Teconologia i Cultura, 36, 4-13.

Torres i Capell, M. (1999). La formació de la urbanística metropolitana de Barcelona. L'urbanisme de la diversitat. Barcelona: MMAMB. 
Trilla, C. (1997). La Barcelona metropolitana: transformacions generades per l'ocupació residencial. Revista econòmica de Catalunya, 33.

Uihlein, A., y Eder, P. (2010). Policy options towards an energy efficient residential building stock in the EU-27. Energy and Buildings, 42, 791-798.

UK Government. Statistics. Recuperado de https://www.gov.uk/government/statistics

Urteaga, L. (2003). El proceso de electrificación en Cataluña (1881-2000). En S. Tarragó (Ed.), Obras Públicas en Cataluña. Presente, pasado y futuro (pp. 355-376). Barcelona: Real Academia de Ingeniería.

Urteaga, Luis (1998). El consumo de electricidad en Barcelona, 1897-1935. En Capel, H. y Linteau P. A. (Dirs.) Barcelona-Montreal. Desarrollo urbano comparado (pp. 259-283). Barcelona: Publicacions Universitat de Barcelona.

Valls, X. (2001). Quan l'Habitatge fa ciutat. Barcelona: Aula Barcelona.

Wilson, B. (2013). Urban form and residential electricity consumption: Evidence from Illinois, USA. Landscape and Urban Planning, 115, 62-71. 